\title{
Translation of Three Short Papers by Grete Hermann
}

\author{
Guido Bacciagaluppi ${ }^{1}$
}

Published online: 27 November 2020

(C) The Author(s) 2020

After a number of years of relative neglect, it is now becoming apparent that Grete Hermann (1901-1984) was one of the most accomplished neo-Kantian philosophers of the last century -in part thanks to the recent publication of two volumes on and of her work, one in English (Crull and Bacciagaluppi 2017) and one in German (Herrmann 2019), both reviewed in this issue. The latter in particular contains Hermann's entire output on modern physics and philosophy of science.

Below I translate the three shortest papers by Hermann in that volume, which I introduce here. They provide quick but fascinating glimpses into some of Hermann's ideas on philosophy of science, quantum mechanics and transcendental idealism. They are: from 1935 a book review of Popper's Logik der Forschung (the original German edition of The Logic of Scientific Discovery), from 1936 a comment on Schlick's posthumously published talk 'Quantentheorie und Erkennbarkeit der Natur' ('Quantum Theory and Knowability of Nature') and from 1937 a short summary of Hermann's ideas on the relation between Kant's philosophy and modern physics (specifically electrodynamics, the special and general theories of relativity and quantum mechanics) presented at the Congrès Descartes in Paris. ${ }^{1}$

\section{Popper Review}

Popper had published Logik der Forschung in late 1934 (with the impressum of the following year, Popper 1935). The physics journal Physikalische Zeitschrift had originally commissioned a review from Carl Friedrich von Weizsäcker, who had however declined and recommended Hermann instead, because he had just been involved in a controversy with Popper in the pages of Die Naturwissenschaften (Popper and Weizsäcker 1934). Weizsäcker had pointed out a technical error in an ill-fated attempt by Popper to show the incompleteness of quantum mechanics. A thought experiment was supposed to allow one to reconstruct both the position and the momentum of one particle by appropriate measurements on another particle that had collided with it (but without being able to select

\footnotetext{
${ }^{1}$ Herrmann (2019, 269-271, 273-274 and 379-381, respectively). Translations in this introduction are mine and all emphases within them are original.
}

Guido Bacciagaluppi

g.bacciagaluppi@uu.nl

1 Descartes Centre for the History and Philosophy of the Sciences and the Humanities, Utrecht University, Utrecht, Netherlands 
which particle of an ensemble had these precise values). Thus-much like EPR the following year (Einstein, Podolsky and Rosen 1935)_-Popper wanted to show that quantum mechanics was correct (because ensembles violating the uncertainty relations could not be prepared) but incomplete (because individual particles within these ensembles had precise values of position and momentum). ${ }^{2}$

Hermann singles out two elements that play a crucial role in Popper's philosophy of science: Popper's falsificationism (which she summarises with some sensitivity) and his notion of the theory-ladenness of observation-both approvingly. Indeed, Hermann is firmly committed to the idea that there are no pure observations. But, as a Kantian, she believes inherent theoretical elements to be a priori and rejects Popper's idea that basic statements are stipulations, which for her debases science 'to a blind play of dogmatic whimsy'.

Hermann then goes on to criticise what she describes as Popper's 'only example treated in detail-the interpretation of Heisenberg's uncertainty relations'. She does not summarise the controversy between Popper and Weizsäcker, but identifies the reason for Popper's mistake as being his reliance on the probabilistic interpretation of quantum mechanical wave functions as relating to ensembles of systems. (Indeed, the ensemble interpretation of probability pervades the entire Logik der Forschung. ${ }^{3}$ )

What Popper neglects, according to Hermann, is that this interpretation of wave functions as providing statistical descriptions of ensembles stands in a complementary relationship to their use as providing state descriptions of individual systems, which are thereby also subject to the uncertainty relations. These comments shed light also on her own views on quantum mechanics, because this is the first place where she explicitly talks of the complementarity between these two aspects of the quantum mechanical description.

\section{Comment on Schlick}

Schlick's talk on 'Quantentheorie and Erkennbarkeit der Natur' (Schlick 1936) was his contribution to the Second International Congress on the Unity of Science, devoted to 'The Problem of Causality'. It was held in Copenhagen 21-26 June 1936, under the presiding genius of Niels Bohr among others. Schlick, however, was not present when his talk was read to the congress-in fact he had been murdered in Vienna on 22 June.

The talk itself argues very lucidly that the limitations on the possibility of knowledge that are imposed by quantum mechanics are not subjective limitations in the sense that there should remain something unknown but unknowable - as arguably for Kant the knowledge of things in themselves. "The limit of knowability is at the same time the limit of lawlikeness in nature" (Schlick 1936, 319). Measurement does not disturb already existing features of physical systems, nor does it force these to acquire such features. We observe only

\footnotetext{
${ }^{2}$ Popper discussed this thought experiment also in Logik der Forschung (Popper 1935, Appendices VI and VII). For further details, see e.g. Frappier (2017) and Bacciagaluppi and Crull (2021, Sect. 1.4, esp. 1.4.4). For related correspondence between Hermann and Weizsäcker, see Letters 14 and 15 (as well as 21) in Herrmann (2019).

${ }^{3}$ It was only in the 1950 s that Popper was to propose his interpretation of singular probabilities as propensities, a notion that appears repeatedly in the added footnotes and appendices in The Logic of Scientific Discovery (Popper 1959).
} 
measurement results and claims that a system has some position or momentum when these quantities are 'indeterminate' are strictly meaningless (Schlick 1936, 321-322).

Similarly, Schlick wishes to establish that, insofar as the limitations imposed by quantum mechanics suggest also limitations for knowability in other parts of nature, e.g. the life sciences, these are again limitations on what there $i s$ to be known. They do not leave room for, say, "the so-called freedom of the will or the assumption of spiritual substances" $(1936,317)$, or the idea that "a full knowledge of life processes might perhaps remain precluded to us because the precise observations required for such knowledge would disturb the life processes themselves" $(1936,323)$.

Schlick is keen to establish in particular that the latter is not what Niels Bohr is suggesting with his ('truly deep') remarks about life $(1936,318)$. Rather, so Schlick, Bohr's remarks should be interpreted in the following sense. Even though physical (indeed classical) concepts are indispensable in describing results of observations, we may expect any physical concepts to prove inadequate in the description of life processes, just as classical concepts have proved inadequate in the description of physical processes $(1936,326)$.

Hermann appreciated Schlick's paper, which according to her "was the best that was presented at this congress from the positivist side", ${ }^{4}$ but not its criticism of Kant-including the implicit criticism of causality. She took her comment as the opportunity to clarify these issues based on her own work on quantum mechanics and on transcendental idealism.

Hermann points out the apparent tensions among some of the features of quantum mechanics discussed by Schlick and claims that these get resolved if one understands quantum mechanical descriptions as relative to a context of observation. This is Hermann's central interpretational move and the one that reconciles Kant and quantum mechanics.

Indeed, for Hermann, Bohr's indispensability of classical concepts is the same as the necessity of Kant's a priori notions. But—in what is in fact a Friesian element-she understands the criteria of application of Kant's notions to be a matter open to empirical investigation. The lesson of quantum mechanics is that classical notions can be applied (within the limits of the uncertainty relations) only relative to observational contexts and not in the passage between one context and the next. In this sense, the limits of knowledge discussed by Kant turn out to agree with those imposed by quantum mechanics. In particular, the principle of causality is vindicated, because it finds strict application within each observational context. ${ }^{5}$

Hermann does not give the details of her arguments here-referring instead to her main essay on quantum mechanics, 'Die naturphilosophischen Grundlagen der Quantenmechanik' (Herrmann 2019, 205-258) ('Natural-philosophical Foundations of Quantum Mechanics' (Crull and Bacciagaluppi 2017, 239-278)). But she makes a noteworthy if passing remark about the apparent 'collapse' of the wave function: it is not a real physical process, because among other things it would have to propagate faster than light. This is a criticism of collapse that tends to be missing from the writings of other proponents of 'Copenhagen' views like Bohr or Heisenberg. ${ }^{6}$

\footnotetext{
${ }^{4}$ Grete Hermann to Heinrich Scholtz and Adolf Kratzer, 8 July 1936 (Herrmann 2019, Letter 28).

5 For more on Hermann's neo-Kantianism, see Paparo (2017), Crull (2017) and Cuffaro (2020), as well as Bacciagaluppi (in preparation a).

6 This criticism is spelled out in more detail in Hermann's own discussion of the EPR paper (and was perhaps prompted by it). See again her letter to Scholtz and Kratzer of two weeks later (Herrmann 2019, Letter 28), as well as Bacciagaluppi (in preparation b).
} 


\section{Congrès Descartes}

Hermann was clearly interested in the dialogue with the logical positivists. In particular, besides her participation in the Unity of Science congress and active contacts with the Berlin Circle, ${ }^{7}$ Hermann was busy organising a meeting in Heidelberg for September 1936, where major approaches to the theory of knowledge were to have been presented by herself, by Schlick and by the prominent logicist Heinrich Scholz. While the meeting took place on a smaller scale (in particular without Schlick), Hermann presented her results there and published them in 1937 as 'Über die Grundlagen physikalischer Aussagen in den älteren und den modernen Theorien' ('On the Foundations of Physical Statements in the Older and the Modern Theories') (Herrmann 2019, 275-334), which is the most detailed statement of her position in natural philosophy. It is unclear whether Hermann attended the Third Congress in Paris at the end of July 1937 (Otto Neurath had invited her on 10 June, see again the catalogue of Hermann's Nachlass), but she appears to have organised a small private philosophy meeting there a few days later, as a follow-up to the Heidelberg meeting. ${ }^{8}$ Between the Third Congress and that meeting (if it took place), Hermann also presented her position at the Ninth International Congress of Philosophy (Congrès Descartes). The brief published contribution to the proceedings is the third paper translated here.

The position Hermann summarises is an extension of her work on quantum mechanics. She had first provided an analysis of special and general relativity in another essay, 'Die Bedeutung der modernen Physik für die Theorie der Erkenntnis' ('The Significance of Modern Physics for the Theory of Knowledge') (Herrmann 2019, 325-377), which was awarded a prize from the Saxon Academy of Sciences on the same fateful 22 June 1936. There she argued that while formally special and general relativity could provide an absolute description in terms of Minkowskian manifolds, the bridge between the formalism and the data of perception was provided by the intuitions of space and time applied in each (global or local) inertial system. In 'Über die Grundlagen physikalischer Aussagen...' she then extended the analysis further, starting from a (Friesian) analysis of the theoretical elements with which we organise our everyday experience-and noting that they closely match the mechanical world picture of classical physics - then examining where electrodynamics, relativity and quantum mechanics appear to depart from them and arguing that in fact they do not. ${ }^{9}$

Hermann's conclusion is that, where modern physics departs from classical physics, it is always and only by relinquishing the assumption that in the attempt to connect the data of perception into a body of physical knowledge, the Kantian notions can be applied uniformly across all contexts of observation. She presents this as fitting into a reading of transcendental idealism along the lines of the neo-Kantianism of Fries and her own teacher Nelson: the a priori principles apply only to the objects of our finite observations, which 'cut' through the fundamentally unintuitive structure of relations described by physics. This, however, glosses over the novelty of Hermann's approach in which the criteria of application of the principles may depend crucially on the different contexts-ensuring objectivity but not at the price of absolutism.

\footnotetext{
7 Cf. Milkov (2008, 57), who cites Danneberg and Schernus (1994, 396-397, footnote 26). There is further a report in the Deutsche Allgemeine Zeitung of 1 February 1935 of a talk by Hermann for the Berlin Circle on 'Korrektur des Kausalprinzips' ('Correction to the Causality Principle') (see the catalogue of Hermann's Nachlass in the Archiv der sozialen Demokratie, Bad Godesberg).

8 Cf. Letters 33 and 38 in Herrmann (2019).

9 Cf. the exchange with Weizsäcker on this approach in Letters 34, 35 and 39 in Herrmann (2019).
} 
After the war, Hermann was to direct her main efforts towards the reconstruction of Germany's education system, but she continued to work on her revised understanding of transcendental idealism and its repercussions not only for natural philosophy but also for the debates on life, free will and ethical and political responsibility.

Open Access This article is licensed under a Creative Commons Attribution 4.0 International License, which permits use, sharing, adaptation, distribution and reproduction in any medium or format, as long as you give appropriate credit to the original author(s) and the source, provide a link to the Creative Commons licence, and indicate if changes were made. The images or other third party material in this article are included in the article's Creative Commons licence, unless indicated otherwise in a credit line to the material. If material is not included in the article's Creative Commons licence and your intended use is not permitted by statutory regulation or exceeds the permitted use, you will need to obtain permission directly from the copyright holder. To view a copy of this licence, visit http://creativecommons.org/licenses/by/4.0/.

\section{References}

Archiv der sozialen Demokratie, Bad Godesberg (Germany), Nachlass Grete Henry-Hermann, 1/GHAJ.

Bacciagaluppi, G. (in preparation a). Kantianism with a Human Face: Grete Hermann's critical philosophy, in preparation.

Bacciagaluppi, G. (in preparation b). Better than Bohr: Grete Hermann and the Copenhagen interpretation, in preparation.

Bacciagaluppi, G., \& Crull, E. (2021). The Einstein Paradox: The Debate on Nonlocality and Incompleteness in 1935. Cambridge: CUP.

Crull, E. (2017). Hermann and the Relative Context of Observation. In E. Crull \& G. Bacciagaluppi (Eds.), Grete Hermann-Between Physics and Philosophy. Studies in History and Philosophy of Science (Vol. 42, pp. 149-169). Dordrecht: Springer.

Crull, E., \& Bacciagaluppi, G. (Eds.) (2017). Grete Hermann-Between Physics and Philosophy. Studies in History and Philosophy of Science, (Vol. 42). Dordrecht: Springer.

Cuffaro, M. E. (2020). Grete Hermann, Quantum Mechanics and the Evolution of Kantian Philosophy. In J. Peijnenburg \& A. A. Verhaegh (Eds.), Women in the History of Analytic Philosophy. Dordrecht: Springer.

Danneberg, L., \& Schernus, W. (1994). Die Gesellschaft für wissenschaftliche Philosophie. In L. Danneberg, A. Kamlah, \& L. Schäfer (Eds.), Hans Reichenbach und die Berliner Gruppe (pp. 391-412). Braunschweig: Vieweg.

Einstein, A., Podolsky, B., \& Rosen, N. (1935). Can Quantum-mechanical Description of Physical Reality be Considered Complete? Physical Review, 47, 777-780.

Frappier, M. (2017). "In the No-Man's Land Between Physics and Logic": On the dialectical role of the microscope experiment. In E. Crull \& G. Bacciagaluppi (Eds.), Grete Hermann-Between Physics and Philosophy. Studies in History and Philosophy of Science (pp. 85-105). Dordrecht: Springer.

Herrmann, K. (2019). Grete Henry-Hermann: Philosophie-Mathematik-Quantenmechanik. Wiesbaden: Springer.

Milkov, N. (2008). Die Berliner Gruppe und der Wiener Kreis: Gemeinsamkeiten und Unterschiede. In M. Fürst, W. Gombocz and C. Hiebaum (Eds.), Analysen, Argumente, Ansätze. Beiträge Zum 8. Internationalen Kongress der Österreichischen Gesellschaft für Philosophie in Graz. (pp. 55-63). Frankfurt: Ontos.

Paparo, G. (2017). Understanding Hermann's Philosopy of Nature. In E. Crull \& G. Bacciagaluppi (Eds.), Grete Hermann-Between Physics and Philosophy. Studies in History and Philosophy of Science (Vol. 42, pp. 35-51). Dordrecht: Springer.

Popper, K. (1935). Logik der Forschung. Wien: Springer.

Popper, K. (1959), The Logic of Scientific Discovery. London: Hutchinson. Reprint: London and New York: Routledge (2002). Translation with added material of Popper (1935).

Popper, K., \& von Weizsäcker, C. F. (1934). Zur Kritik der Ungenauigkeitsrelationen. Die Naturwissenschaften, 22(48), 807-808.

Schlick, M. (1936). Quantentheorie und Erkennbarkeit der Natur. Erkenntnis, 6(5/6), 317-326.

Publisher's Note Springer Nature remains neutral with regard to jurisdictional claims in published maps and institutional affiliations. 